Article

\title{
Optical and Thermal Investigations of New Schiff Base/Ester Systems in Pure and Mixed States
}

\author{
Abeer S. Altowyan ${ }^{1}$, Hoda A. Ahmed ${ }^{2,3, *(\mathbb{D})}$, Sobhi M. Gomha ${ }^{2,4}$ (D) and Ayman M. Mostafa ${ }^{5,6,7}$ \\ 1 Department of Physics, College of Science, Princess Nourah bint Abdulrahman University, \\ Riyadh 11671, Saudi Arabia; asaltowyan@pnu.edu.sa \\ 2 Department of Chemistry, Faculty of Science, Cairo University, Cairo 12613, Egypt; sm.gomha@iu.edu.sa \\ 3 Chemistry Department, College of Sciences, Yanbu, Taibah University, Yanbu 30799, Saudi Arabia \\ 4 Chemistry Department, Faculty of Science, Islamic University in Almadinah Almonawara, \\ Almadinah Almonawara 42351, Saudi Arabia \\ 5 National Research Centre, Spectroscopy Department, Physics Division, El-Buhouth St., Dokki, \\ Giza 12622, Egypt; aymanmdarwish@gmail.com \\ 6 Laser Technology Unit, Centre of Excellence for Advanced Sciences, National Research Centre, \\ Dokki, Giza 12622, Egypt \\ 7 Center for Imaging and Microscopy (CIM), Zewail City of Science and Technology, October Gardens, \\ 6th of October, Giza 12578, Egypt \\ * Correspondence: ahoda@sci.cu.edu.eg
}

Citation: Altowyan, A.S.; Ahmed, H.A.; Gomha, S.M.; Mostafa, A.M. Optical and Thermal Investigations of New Schiff Base/Ester Systems in Pure and Mixed States. Polymers 2021, 13, 1687. https://doi.org/10.3390/ polym13111687

Academic Editors: Seung-Hee Lee and Gi-Dong Lee

Received: 13 May 2021

Accepted: 20 May 2021

Published: 22 May 2021

Publisher's Note: MDPI stays neutral with regard to jurisdictional claims in published maps and institutional affiliations.

Copyright: (c) 2021 by the authors. Licensee MDPI, Basel, Switzerland. This article is an open access article distributed under the terms and conditions of the Creative Commons Attribution (CC BY) license (https:/ / creativecommons.org/licenses/by/ $4.0 /)$.

\begin{abstract}
New mesomorphic series, 4-hexadecyloxy phenyl-imino-4'-(3-methoxyphenyl)-4"alkoxybenzoates $(\mathbf{A} n)$, were prepared and investigated with different thermal and mesomorphic techniques. The synthesized homologous series constitutes four members that differ from each other in the terminal length of flexible chain $(n)$ attached to phenyl ester moiety, which varies between $n=6,8,10$, and 12 carbons. A lateral $\mathrm{CH}_{3} \mathrm{O}$ group is attached to the central benzene ring in the meta position with respect to the ester moiety. Molecular structures of all newly prepared homologues were elucidated via FT-IR, ${ }^{1} \mathrm{H}$ and ${ }^{13} \mathrm{C}$ NMR spectroscopy. Mesomorphic and thermal properties were examined by differential scanning calorimetry (DSC), thermogravimetric analysis (TGA) and the mesophases identified by polarized optical microscopy (POM). DSC and POM examinations revealed that all members of the present series $(\mathrm{A} n)$ exhibit a purely enantiotropic nematic $(\mathrm{N})$ phase. Comparative evaluations and binary phase diagrams were established between the present homologues and their corresponding shorter one $(\mathbf{B} n)$. The examination revealed that, the length of the flexible alkoxy chain incorporated into the phenylimino moiety is highly effective on the temperature range and stability of the mesophase observed. With respect to the binary mixtures $\mathbf{A} n / \mathbf{B} n$, the exhibited $\mathrm{N}$ phase showed to cover the whole composition range with eutectic behavior.
\end{abstract}

Keywords: schiff base/ester; Lateral methoxy; optical properties; nematic stability; binary phase diagram

\section{Introduction}

The optical and mesomorphic characters of compounds are known to be mainly dependent on their architecture, in which a slight change in the molecular geometry is accompanied with considerable changes in their optical characteristics [1-6]. In order to understand the relationship between the molecular shape and the liquid crystalline (LC) properties is, in principle, a fundamental task in condensed material science, where it enables scientists to prepare LC materials with the desired properties. The design of new non-symmetrical compounds is associated with new molecular parameters. The first LC material prepared at room temperature, 4-methoxybenzylidene- $4^{\prime}$-butylaniline (MBBA), was prepared by Kelker, H., et al. [7]. Several calamitic thermotropic LC Schiff base/ester LCs have been investigated and are often evaluated their interesting optical phenomena [8-14]. The geometrical studies indicated that each of the orientations of 
the ester within the rigid portion of the molecule, the location of azomethine and ester linking groups, laterally protruded groups, and the terminal flexible chain length, have important roles in the enhancement of the phase thermal stability. The rigid shape of the azomethine molecule makes them essential for exhibiting the mesomorphic phase with a high thermal stability [15-17]. Moreover, their interesting properties provide the possibility of molecular mobility in response to light or heat, thus offering many opportunities in photonic applications [18-21].

Generally, as the breadth of the molecule is increased, the thermal transitions of formed mesophases will be reduced [22]. In such cases, the inclusion of a compact polar lateral group to the main skeleton of the molecule influences the physical properties of the resulting LC material, such as the melting point, phase transition temperatures, morphology, dielectric anisotropy and dipole moment [23-26]. The small volume of lateral substituent enables its attachment into the mesomorphic shape of the molecule without being sterically disrupted, and accordingly, the LC mesophases can still be observed. On the other hand, the increased intermolecular separation, affected by the addition of the lateral group, broadens the core portion and leads to a reduction in the lateral interactions [27]. Furthermore, the longer flexible terminal chains in the molecules enhance their orientation in parallel alignments [28]. Actually, the lateral or terminal polar substituents induce the mesomeric properties of wide numbers of Schiff bases/ester derivatives [16,29]. The conformation of the alkyl terminal chain causes highly effects in the thermal and physical properties as the - $\mathrm{CH} 2$ - and - $\mathrm{CH} 3$ numbers in the terminal chain changes from odd to even in LC mesophases; this effect is named the odd-even effect in a series [30]. Compounds with an odd number of $C$ atoms in the terminal alkyl chain are more flexible than molecules with an even number of $\mathrm{CH} 2$ units. This behavior results in a less uniform orientation of LC materials [31]. Moreover, in the total chain length, odd and even numbers of $C$ atoms result in a different macroscopic characteristics $[31,32]$. Thus, the odd-even effect offers a new mode to optimize mesophase and optical properties [33].

In order to dropping the melting temperature of a liquid crystalline material to be close to room temperature, the mixing of two or more components was established. The mixtures of LC show mesophase transitions and thermal properties that differ from their individual components. Mixing of two or more LC components leads to tuning the needed characteristics of interest [34-42]. Moreover, the binary LC mixtures could be better established for many fields in certain applications [43]. Thus, the mesomorphic characterization of such mixtures is of considerable interest [44-46]. These types of mixtures have been shown to achieve lower melting points [46]. Furthermore, the mesophase temperature range, observed for the eutectic mixture, is wider than either of its pure components [44-47].

In our previous work [48], the thermal and optical properties of 4-hexyloxyphenylimino$4^{\prime}$-(3-methoxyphenyl)-4"-alkoxy- benzoates were investigated and the results showed that all the homologues studied possess the nematic mesophase enantiotropically. Herein, the aim of present work is to synthesize a homologous series; namely, 4-hexdecyloxyphenylimino-4'-(3methoxyphenyl)-4"-alkoxy- benzoates, $\mathbf{A} n$, of long terminal alkyl chain length connected to the end of phenyl azomethine linkage, with different alkoxy terminal groups of different lengths, on the other end of the molecule (Scheme 1). The study will be extended to investigate their mesomorphic behavior and the effect of the terminal length of alkoxy chain (n) on their mesomorphic phenomena. Finally, binary mixtures of different azomethine homologues bearing different terminal chain lengths were investigated in order to evaluate the mesophase behavior in their mixed states. 


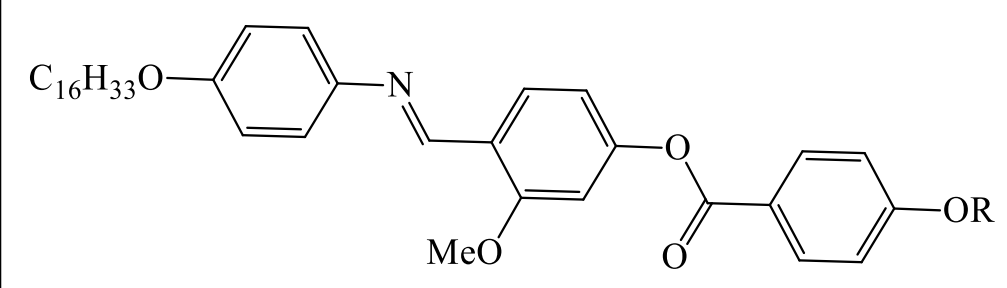

An

$\mathrm{R}=\mathrm{C}_{\mathrm{n}} \mathrm{H}_{2 \mathrm{n}+1}, \mathrm{n}=8,10,12$ and 16 carbons

Scheme 1. Prepared homologues series, An.

\section{Experimental}

\subsection{Synthesis}

Schiff base and hydrazone derivatives are well known as valuable intermediates in the synthesis of many organic compounds that are used in a multitude of applications [49-57]. A series of new laterally methoxy Schiff base derivatives A $n$ were prepared according to the following Scheme 2:

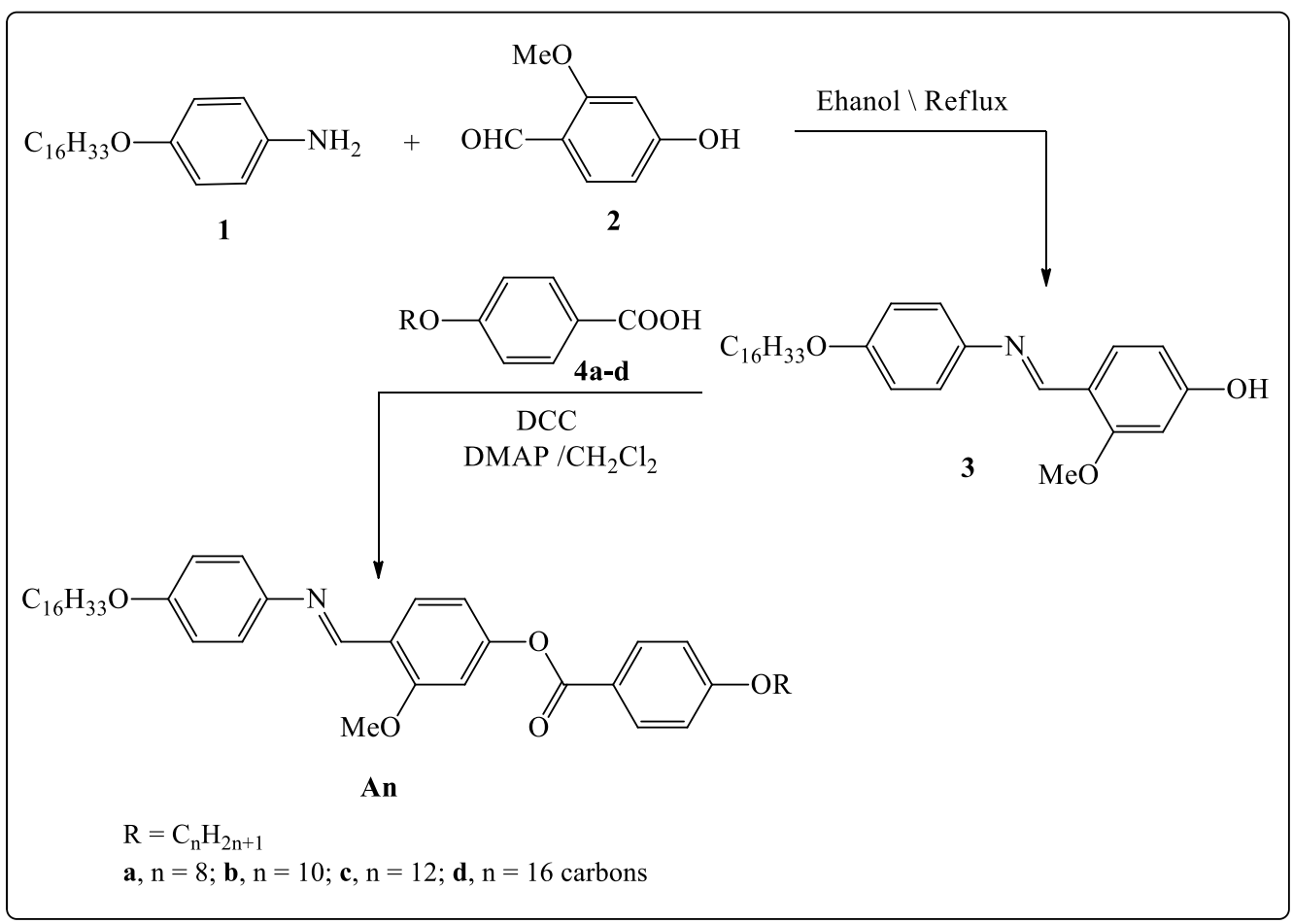

Scheme 2. Synthesis route of title compounds An.

2.1.1. Synthesis of 4-((4-(Hexadecyloxy)Phenyliminomethyl)-3-Methoxyphenol (3)

Details were inserted in Supplementary Data.

2.1.2. Synthesis of 4-((4-(Hexadecyloxy)Phenyl)Imino M thyl)-3-Methoxyphenyl4Alkoxybenzoate, An

Details were inserted in Supplementary Data.

Elemental analyses, Infrared spectra (FT-IR) and ${ }^{1} \mathrm{H}-\mathrm{NMR}$, for the designed series were agreement with the structures assigned. ${ }^{1} \mathrm{H}-\mathrm{NMR}$ results displayed the expected integrated aliphatic to aromatic proton ratios in all prepared compounds. 


\section{Results and Discussion}

\subsection{Mesomorphic Behavior of Investigated Series, $\mathbf{A} n$}

The mesophase transition temperatures and optical behaviors of the investigated laterally methoxy homologous series were evaluated by DSC and POM measurements. A DSC thermogram of the homologue $\mathbf{A} 8$ is displayed in Figure 1 upon heating and cooling cycles, as a representative example. Two transition peaks were observed in Figure 1. The nematic mesophase was observed either from $\mathrm{Cr} \rightarrow \mathrm{N}$ on heating, or from $\mathrm{I} \rightarrow \mathrm{N}$ on cooling. The position of the endothermic and exothermic peaks observed depended on the length of the attached terminal alkoxy chain. The endothermic peaks were ascribed to mesophase transition upon heating and the exothermic peaks upon cooling. Optical images under POM confirm the DSC measurements. Figure 2 illustrates the POM nematic phase texture of the $\mathbf{A} 8$ homologue, as an example. The phase transition temperatures, as driven from measurements via DSC, and their associated enthalpies of transitions for all of the homologues series, $\mathbf{A} n$, are collected in Table 1 . In order to investigate the effect of the length of the terminal alkoxy chain $(n)$ on the mesomorphic properties of prepared compounds, Figure 3 displays their relationship. As shown from Table 1 and Figure 3, all the synthesized homologues are mesomorphic in nature with enantiotropic properties and their thermal mesophase stability (the maximum temperature stability of the phase) is dependent on their terminal flexible alkoxy-chain length $(n)$. Moreover, all were shown to possess a pure nematic phase. It can also be seen from Table 1 and Figure 3 that the melting temperature of compounds varied as usual randomly with $n$. The shortest terminal length member (A8) exhibits an $\mathrm{N}$ phase with thermal stability $\left(\boldsymbol{T}_{\mathrm{N}-\mathrm{I}}\right)$ and a temperature range $(\Delta T)$ of 112.9 and $38.0^{\circ} \mathrm{C}$, respectively. For $\mathbf{A} 10$, it possesses also the enantiotropic $\mathrm{N}$ mesophase with nematogenic stability and ranges that are nearly 112.2 and $35.5^{\circ} \mathrm{C}$, respectively. The homologue A12 possesses less thermal N stability $\left(110.1^{\circ} \mathrm{C}\right)$ and the $\mathrm{N}$ mesophase temperature range is nearly $37.0^{\circ} \mathrm{C}$. The longest derivative A16 exhibits the lowest thermal $\mathrm{N}$ stability $\left(108.7^{\circ} \mathrm{C}\right)$ and the highest nematogenic temperature range nearly $39.0^{\circ} \mathrm{C}$. In general, the shape of the molecule, polarizability and the dipole moment of the designed molecule are highly impacted by the electronic nature of the terminal substituents. Moreover, the mesomorphic behavior is influenced by an increment in the polarity and/or polarizability of the molecular mesogenic cores. The nematogenic range of the present investigated homologues series decreases in the order: A16 > A8 $>$ A12 > A10. Mesomorphic phenomena indicate the sharing of these factors with different extents. The aggregation due to the oxygen of the alkoxy chain and the ester carbonyl moiety and the cohesive forces between molecules are important factors that determine the observed nematic phase [58,59].

Table 1. Mesomorphic transition temperatures $\left({ }^{\circ} \mathrm{C}\right)$, enthalpy $(\Delta \mathbf{H})$ of transition, $\mathrm{kJ} / \mathrm{mole}$, and normalized entropy $(\Delta \mathbf{S} / \mathrm{R})$ of transition for homologues $\mathrm{A} n$.

\begin{tabular}{ccccccc}
\hline Comp. & $\boldsymbol{T}_{\mathrm{Cr}-\mathrm{N}}$ & $\boldsymbol{\Delta} \boldsymbol{H}_{\mathrm{Cr}-\mathrm{N}}$ & $\boldsymbol{T}_{\mathrm{N}-\mathrm{I}}$ & $\boldsymbol{\Delta} \boldsymbol{H}_{\mathrm{N}-\mathrm{I}}$ & $\boldsymbol{\Delta}$ & $\Delta \boldsymbol{S}_{\mathrm{N}-\mathrm{I}} / \mathbf{R}$ \\
\hline $\mathbf{A} 8$ & 74.9 & 62.39 & 112.9 & 1.59 & 38.0 & 0.50 \\
\hline A10 & 76.7 & 48.4 & 112.2 & 2.70 & 35.5 & 0.84 \\
\hline A12 & 73.1 & 40.90 & 110.1 & 1.56 & 37.0 & 0.49 \\
\hline A16 & 69.7 & 44.65 & 108.7 & 1.63 & 39.0 & 0.51 \\
\hline
\end{tabular}

$\mathrm{Cr}-\mathrm{N}=$ transition of solid to the nematic phase. $\mathrm{N}-\mathrm{I}=$ transition of nematic to the isotropic liquid phase. $\Delta \mathbf{H}=$ Enthalpy of transition, $\mathrm{kJ} /$ mole derived from DSC peak of transitions; $\Delta \mathrm{S} / \mathrm{R}=\Delta \mathrm{H} / \mathrm{RT}$ is the normalized entropy of transition, unitless (due to the entropy change $\Delta \mathbf{S}$ is divided by $\mathbf{R}=$ gas constant). 


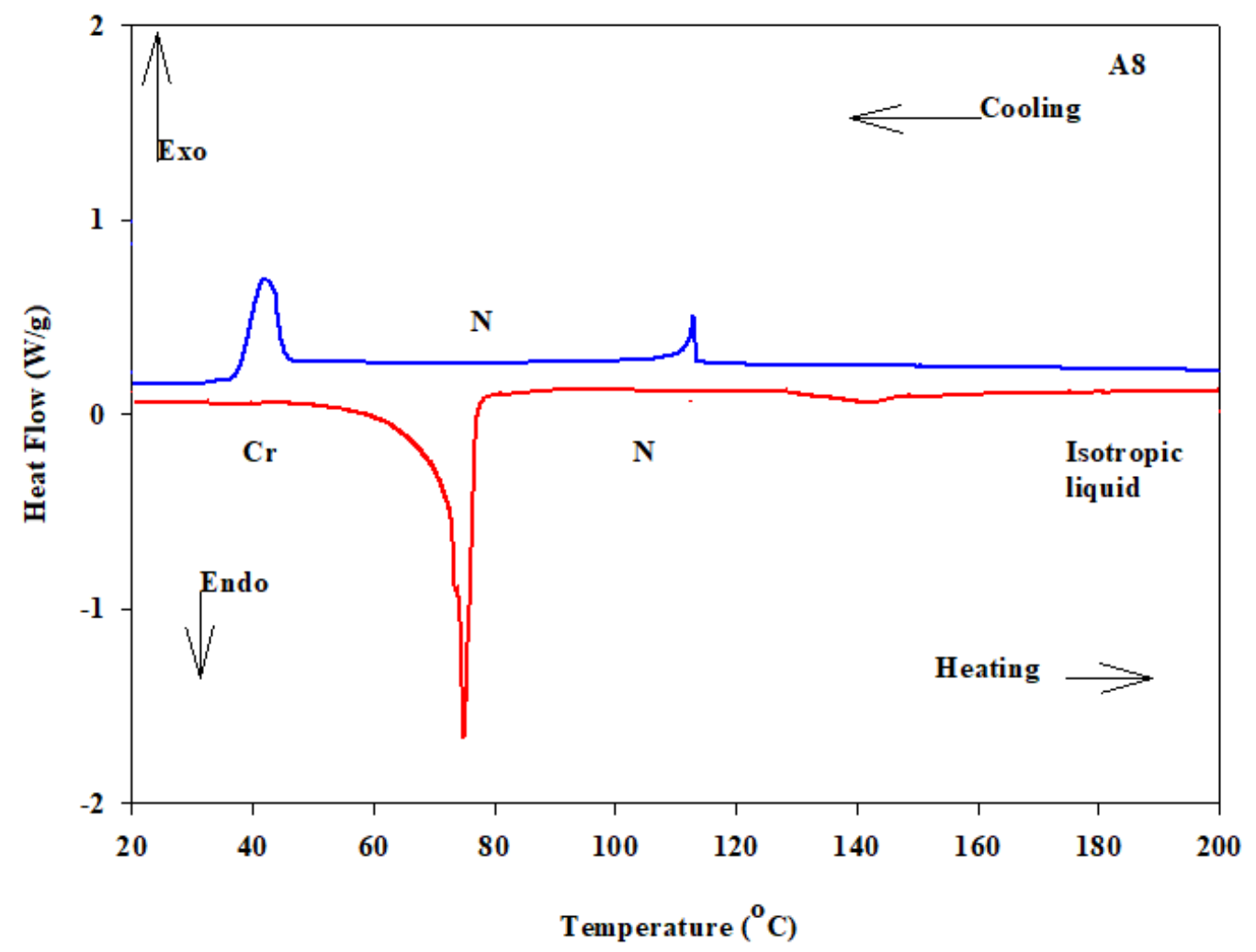

Figure 1. DSC thermograms of homologue $\mathbf{A} 8$ recorded from the second heating and cooling cycles at a rate of $\pm 10^{\circ} \mathrm{C} \min ^{-1}$.
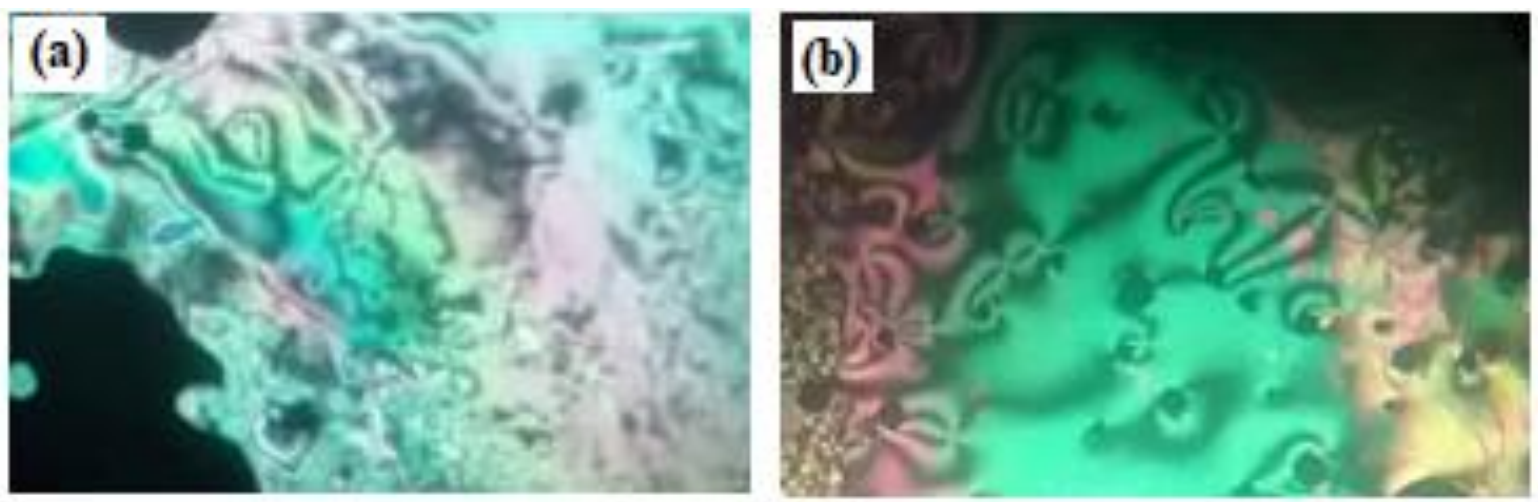

Figure 2. $\mathrm{N}$ mesophase textures observed upon heating under POM for (a) homologue $\mathbf{A} 8$ at $107.0^{\circ} \mathrm{C}$ and (b) homologue A16 at $102.0^{\circ} \mathrm{C}$. 


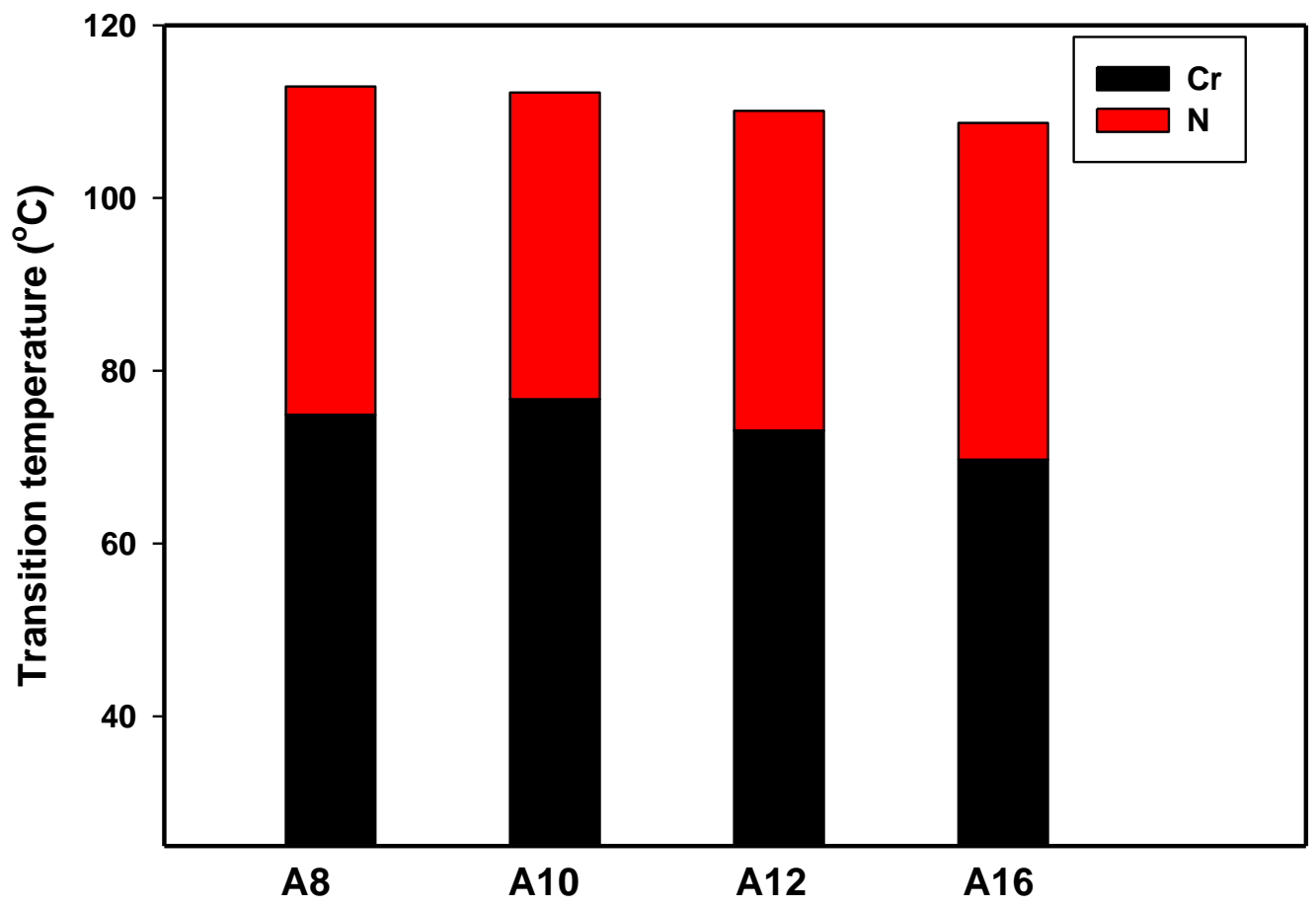

Figure 3. Impact of alkoxy chain length $(n)$ on the mesomorphic behavior of the present investigated series, $\mathbf{A} n$.

The normalized entropy changes $\left(\Delta \mathrm{S}_{\mathrm{N}-\mathrm{I}} / \mathrm{R}\right)$ of the prepared homologous series are summarized in Table 1. The results revealed that the value of the entropy changes is observed to be related, independently, to the chains terminal length $(n)$. The small values observed for the entropy change can be attributed to the decrease in the ratio of length/breadth as a result of their lower anisotropy due to their molecular shape and molecular biaxiality $[60,61]$. The induction, conjugation forces, the specific dipolar interactions, as well as the $\pi-\pi$ stacking interactions, play essential roles in the molecular orientation and thus in the arrangement of molecules, as well as in the formation of the mesophase. Moreover, the thermal cis/trans isomerization of the $-\mathrm{CH}=\mathrm{N}$-linkage was an essential factor in the observed entropy change values. The higher entropy changes of the A10 derivative may be attributed to the increment of its molecular biaxiality in addition to differences in its molecular interactions.

\subsection{Thermal Characterizations}

The thermal stabilities of the prepared compounds ( $\mathrm{A} n)$ were evaluated by thermogravimetric analysis (TG). The TG thermogram and its corresponding derivative (DTG) of the homologue $\mathbf{A} 8$ is displayed in Figure 4, as a representative example. As can be seen from Figure 4, the decomposition takes place through two degradation steps depending on the molecular structure of the compound. The first step occurs in the temperature range $\approx 220-310{ }^{\circ} \mathrm{C}$ and starts at $240{ }^{\circ} \mathrm{C}$ with maximum degradation rate $\left(\mathbf{T}_{\max }\right)$ at $310^{\circ} \mathrm{C}$, indicating that the sample has a high thermal stability, while the second decomposition step occurs between $320^{\circ} \mathrm{C}$ and $380^{\circ} \mathrm{C}$ with maximum degradation rate $\approx 340^{\circ} \mathrm{C}$. The results revealed that the investigated materials possess high thermal stabilities of up to $340^{\circ} \mathrm{C}$, which covers the temperature window of phase transitions. 

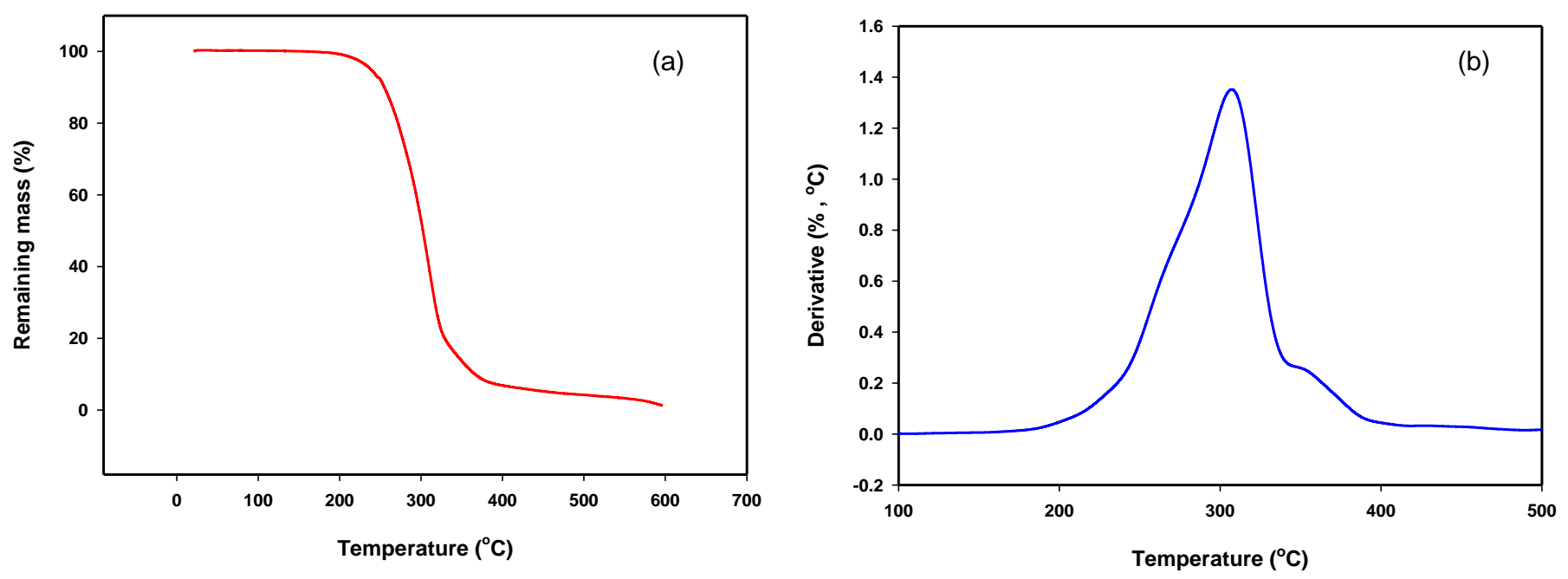

Figure 4. TG (a) and DTG (b) curves of the compound A8.

\subsection{Effect of the Proportionating of the Alkoxy Chain Length on the Mesomorphic Properties}

The terminal alkoxy chain attached to the molecule has an essential role to impact their mesomorphic transitions. In order to analyze the impact of the proportion of the alkoxy chain length, which is connected to the terminal azomethine phenyl moiety, on the mesomorphic phenomena of the series, a comparison was made between the phase behavior of the present long-chain analogues $(\mathrm{A} n)$ and the previously short chain homologues series $\mathbf{B} n$ [48] (Scheme 3) and the correlation is graphically depicted in Figure 5a and their temperature ranges in Figure $5 b$. As can be seen from Figure 5a, the mesomorphic thermal stability of $\mathbf{B} n$ homologues are higher than those of $\mathbf{A} n$. This may be attributed to the influenced mesogenic core dipole moments, which is dependent upon the mesomeric nature of the short chain $\left(\mathrm{CH}_{2}=6\right)$. The mesomorphic range (Figure $5 \mathrm{~b}$ ) of the $\mathbf{B} n$ series exhibits higher temperature ranges than those of $\mathbf{A} n$, except for $n=16$ carbons. The present homologous series $\mathbf{A} n$ showed a wider nematic temperature range than the previously investigated analogues, $\mathbf{B} n$. The constructed comparison revealed that the nematic thermal stability, as well as its temperature range, depends also on the length of the alkoxy chain attached to the phenylimino moiety. The flexibility of the terminal alkoxy chains and the rigidity of phenyl rings in the central backbone are important in the LC phase formation. Moreover, the semi-flexibility of terminals has a big role in the thermal stability of LC phases. That is, as the terminal alkoxy chain length of the molecule increases, the rigidity of the central part will be decreased; so, the linearity of the molecule slightly decreases due to the greater number of configurations of the terminal chains (which lead to the strong terminal interactions).

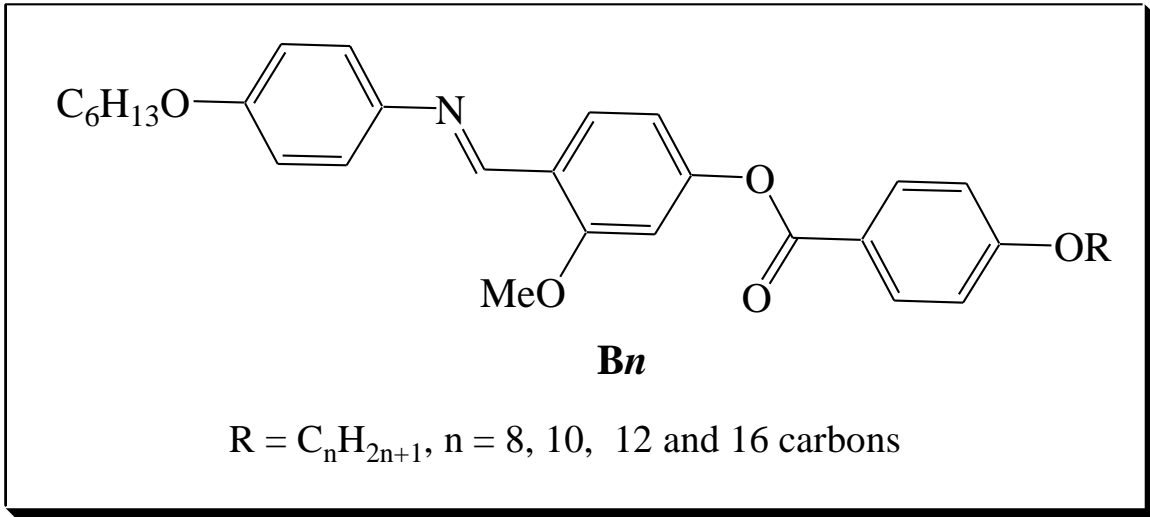

Scheme 3. Homologues series, $\mathbf{B} n$. 

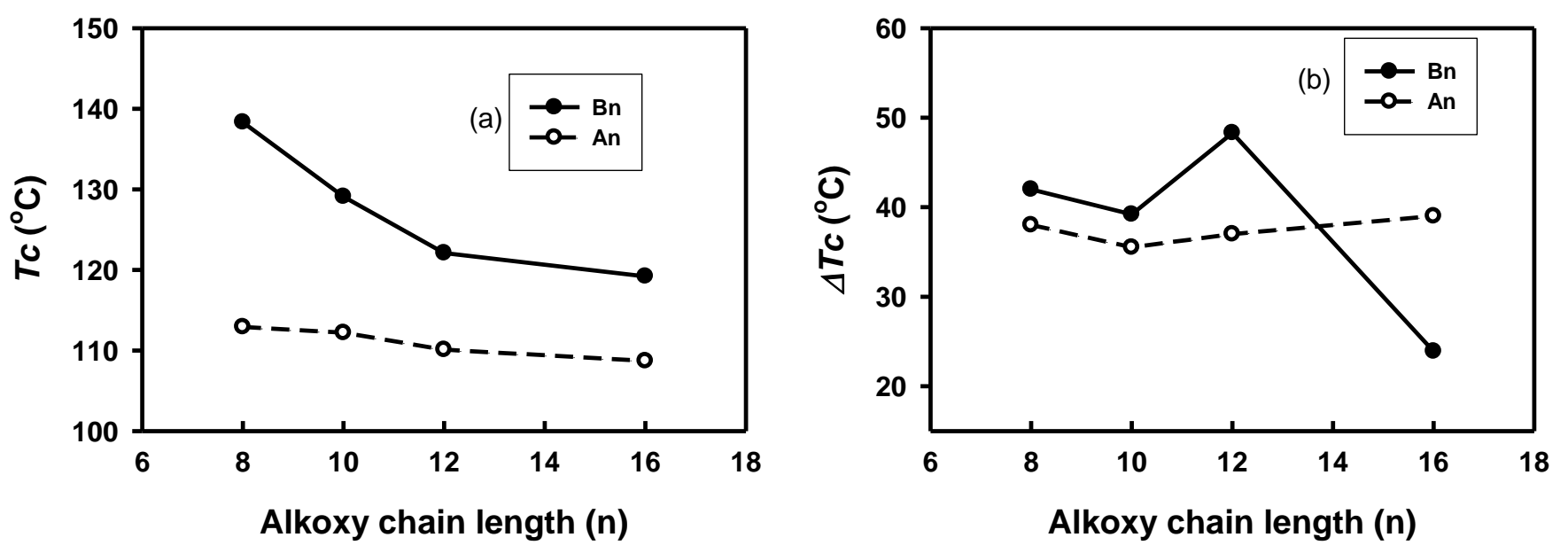

Figure 5. Comparison of $\mathbf{T c}_{\mathbf{c}}(\mathbf{a})$; and $\Delta \mathbf{T c}_{\mathbf{c}}(\mathbf{b})$ of series $\mathbf{A} n$ and $\mathbf{B} n$.

\subsection{Binary Phase Diagrams of Components of Different Terminal Alkoxy Chain Lengths}

The binary mixture phase diagrams are changed depending on the kind of its individual components. The different polarity, as well as the location of the lateral substituent, is the main factors. The goal of such a study was to attain a balance between the two components, which are expected to be improved on mixing, thus resulting in advantageous physical and thermal properties, as well as depression of the melting transitions.

The constructed phase diagrams, derived from measured DSC curves of mixtures, are made from different homologues with different alkoxy chain-lengths and are depicted in Figure $6 \mathrm{a}, \mathrm{b}$. As can be seen from Figure $6 \mathrm{a}, \mathrm{b}$, the mixtures constructed from compounds bearing short alkoxy-chain groups (A8/B8) and the longest terminal chains (A16/B16) were shown to possess the $\mathrm{N}$ phase over the entire composition range. Slight decrements from the ideal behavior are observed for the clearing temperatures of both systems. This may be due to the molecular association disruption, as a result of the dis-similarity of the alkoxy terminal chain lengths, in the two components as is observed in the previously reported binary systems [62]. In both systems, their solid mixtures have eutectic melting temperatures of $69.1{ }^{\circ} \mathrm{C}$ and $55.3{ }^{\circ} \mathrm{C}$ with eutectic compositions 79.9 and $59.6 \mathrm{~mol} \%$ for A8/B8 and A16/B16, respectively. On the other hand, the eutectic mixture of binary system A8/B8 exhibits an $\mathrm{N}$ temperature range of nearly $47.0^{\circ} \mathrm{C}$, while the $\mathrm{N}$ range for the eutectic mixture of the A16/B16 system is about $56.3^{\circ} \mathrm{C}$. It can be concluded that the two mixed analogues $\mathbf{A} n$ and $\mathbf{B} n$ have different aspect ratios, in which one derivative is longer than the other, which may be located in the organized directed geometry; so, the addition of the designed derivatives of $\mathbf{A} n$ are not expected to disturb the molecular arrangement of the shorter homologues $\mathbf{B} n$. Typical DSC curve of heating and cooling scans of the mixture A8/B8 of composition $80 \%$ mol of A8 (at eutectic composition) are displayed in Figure 7. 

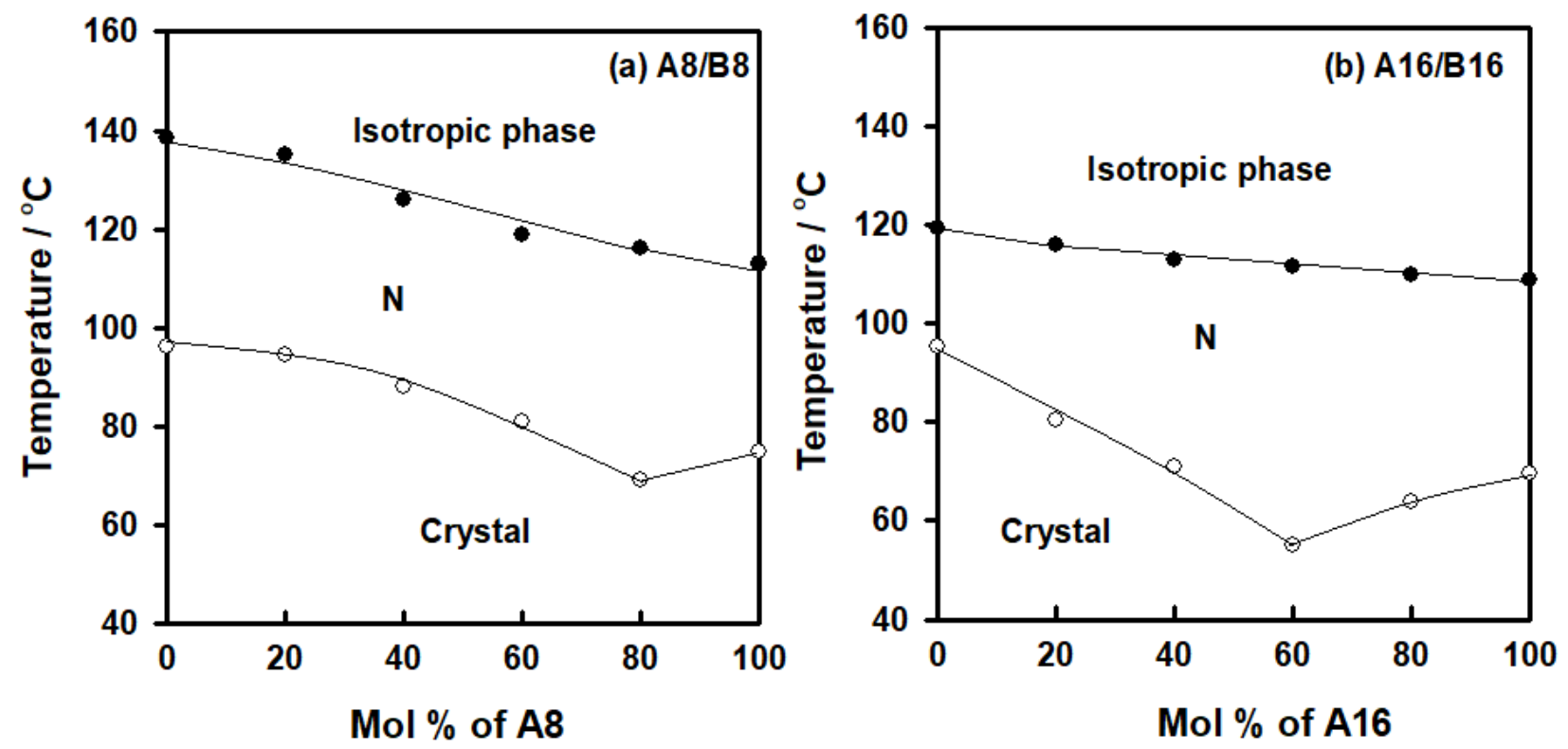

Figure 6. Phase diagrams for systems (a) A8/B8 and (b) A16/B16; the symbol "o" denotes the solid-N phase, "•" N-I phase transition upon second heating scan.

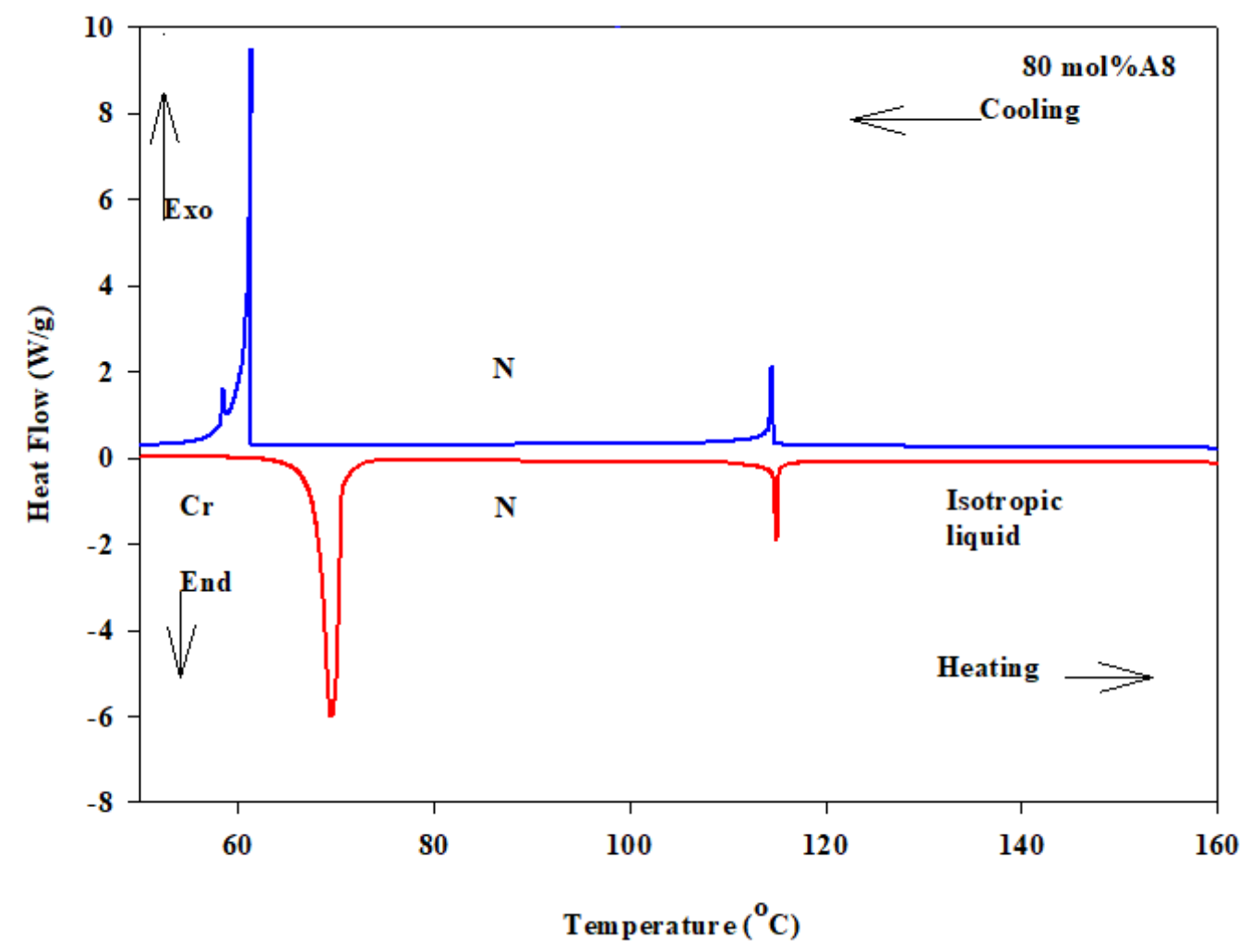

Figure 7. DSC curve of $80 \% \mathrm{~mol}$ of $\mathbf{A} 8$ for system $\mathbf{A} 8 / \mathbf{B} 8$ at a rate of $\pm 10{ }^{\circ} \mathrm{C} \mathrm{min}^{-1}$ recorded upon heating and cooling cycles.

\section{Conclusions}

A new homologue set based on the laterally-methoxy substituted azomethine derivatives was synthesized and investigated with different optical and thermal techniques. Molecular structures were confirmed by FT-IR and NMR spectroscopy. The optical, mesomorphic and thermal properties were determined using DSC, POM, and TGA analyses. The results revealed that all synthesized compounds exhibit only an $\mathrm{N}$ phase irrespective 
of their terminal alkoxy-chain length. Moreover, their thermal stability was examined and shown to cover a higher stability than their mesomorphic transitions. A comparative investigation was made between the present designed series and their corresponding shortchain homologues. The study revealed that the attached flexible chain to the phenylimino portion is more effective on the observed nematic temperature range and stability. The binary phase mixtures of $\mathbf{A} n / \mathbf{B} n$ showed an enantiotropic $\mathbf{N}$ phase covering the whole composition range, with depression in the melting temperature at the eutectic composition.

Supplementary Materials: The following are available online at https:/ /www.mdpi.com/article/10 $.3390 /$ polym13111687/s1. The synthetic and characterization details of investigated compounds.

Author Contributions: Formal analysis, A.S.A., H.A.A. and A.M.M.; funding acquisition, A.S.A.; methodology, H.A.A. and S.M.G.; project administration, A.S.A. and H.A.A.; resources, A.S.A., H.A.A. and S.M.G.; software, A.M.M.; writing—original draft, A.S.A., H.A.A., A.M.M. and S.M.G.; writing-review and editing, H.A.A. and A.S.A. All authors have read and agreed to the published version of the manuscript.

Funding: This research was funded by the Deanship of Scientific Research at Princess Nourah bint Abdulrahman University through the Fast-track Research Funding Program.

Institutional Review Board Statement: Not Applicable.

Informed Consent Statement: Not Applicable.

Data Availability Statement: The data presented in this study are available on request from the corresponding author.

Conflicts of Interest: The authors declare no conflict of interest.

\section{References}

1. Zaki, A.A.; Hagar, M.; Alnoman, R.B.; Jaremko, M.; Emwas, A.-H.; Ahmed, H.A. Mesomorphic, Optical and DFT Aspects of Near to Room-Temperature Calamitic Liquid Crystal. Crystals 2020, 10, 1044. [CrossRef]

2. Abozied, A.M.; Mostafa, A.M.; Abouelsayed, A.; Hassan, A.; Ramadan, A.; Al-Ashkar, E.A.; Anis, B. Preparation, characterization, and nonlinear optical properties of graphene oxide thin film doped with low chirality metallic SWCNTs. J. Mater. Res. Technol. 2021, 12, 1461-1472. [CrossRef]

3. Ahmed, H.A.; Hagar, M.; Alhaddad, O.A.; Zaki, A.A. Optical and Geometrical Characterizations of Non-Linear Supramolecular Liquid Crystal Complexes. Crystals 2020, 10, 701. [CrossRef]

4. Mostafa, A.M.; Mwafy, E.A.; Awwad, N.S.; Ibrahium, H.A. Linear and nonlinear optical studies of Ag/Zn/ZnO nanocomposite thin film prepared by pulsed laser deposition technique. Radiat. Phys. Chem. 2021, 179, 109233. [CrossRef]

5. Abouhaswa, A.S.; Sayyed, M.I.; Altowyan, A.S.; Al-Hadeethi, Y.; Mahmoud, K.A. Synthesis, optical and radiation shielding capacity of the $\mathrm{Sm}_{2} \mathrm{O}_{3}$ doped borate glasses. J. Non-Cryst. Solids 2021, 553, 120505. [CrossRef]

6. Altowyan, A.S.; Abdel-Khalek, S.; Berrada, K. Emission spectrum and geometric phase in de-formed Jaynes-Cummings model. Results Phys. 2020, 16, 102924. [CrossRef]

7. Kelker, H.; Scheurle, B. Eine flüssig-kristalline (nematische) Phase mit besonders nie-drigem Erstarrungspunkt. Angew. Chem. 1969, 81, 903-904. [CrossRef]

8. Kelker, H.; Scheurle, B. A liquid-crystalline (Nematic) phase with a particularly low so-lidification point. Angew. Chem. 1969, 8, 884-885. [CrossRef]

9. Kato, T.; Uchida, J.; Ichikawa, T.; Sakamoto, T. Functional liquid crystals towards the next genera-tion of materials. Angew. Chem. 2018, 57, 4355-4371. [CrossRef] [PubMed]

10. Almomani, M.; Ahmed, N.; Rashid, M.; Almessiere, M.; Altowyan, A. Broadband visible emission from photoelectrochemical etched porous silicon quantum dots containing zinc. Mater. Chem. Phys. 2021, 258, 123935. [CrossRef]

11. Ahmed, N.H.S.; Saad, G.R.; Ahmed, H.A.; Hagar, M. New wide-stability four-ring azo/ester/Schiff base liquid crystals: Synthesis, mesomorphic, photophysical, and DFT approaches. RSC Adv. 2020, 10, 9643-9656. [CrossRef]

12. Al-Mutabagani, L.; Alshabanah, L.A.; Ahmed, H.; Abu Al-Ola, K.; Hagar, M. New Rod-like H-bonded Assembly Systems: Mesomorphic and Geometrical Aspects. Crystals 2020, 10, 795. [CrossRef]

13. Ahmed, H.A.; Hagar, M.; Aljuhani, A. Mesophase behavior of new linear supramolecular hydrogen-bonding complexes. RSC Adv. 2018, 8, 34937-34946. [CrossRef]

14. Ahmed, H.A.; Mansour, E.; Hagar, M. Mesomorphic study and DFT simulation of calamitic Schiff base liquid crystals with electronically different terminal groups and their binary mixtures. Liq. Cryst. 2020, 47, 2292-2304. [CrossRef]

15. El-Atawy, M.A.; Naoum, M.M.; Al-Zahrani, S.A.; Ahmed, H.A. New Nitro-Laterally Substituted Azomethine Derivatives; Synthesis, Mesomorphic and Computational Characterizations. Molecules 2021, 26, 1927. [CrossRef] 
16. Al-Mutabagani, L.; Alshabanah, L.; Ahmed, H.; Alalawy, H.; Al Alwani, M. Synthesis, Mesomorphic and Computational Characterizations of Nematogenic Schiff Base Derivatives in Pure and Mixed State. Molecules 2021, 26, 2038. [CrossRef] [PubMed]

17. Ahmed, H.A.; El-atawy, M.A. Synthesis, Mesomorphic and Geometrical approaches of New non-symmetrical System based on central Naphthalene moiety. Liq. Cryst. 2021. [CrossRef]

18. Yan, J.; Wu, S.-T. Polymer-stabilized blue phase liquid crystals: A tutorial [Invited]. Opt. Mater. Express 2011, 1, 1527-1535. [CrossRef]

19. Ikeda, T. Photomodulation of liquid crystal orientations for photonic applications. J. Mater. Chem. 2003, 13, 2037-2057. [CrossRef]

20. Huang, C.-C.; Hsu, C.-C.; Chen, L.-W.; Cheng, Y.-L. The effect of position of (S)-2-octyloxy tail on the formation of frustrated blue phase and antiferroelectric phase in Schiff base liquid crystals. Soft Matter 2014, 10, 9343-9351. [CrossRef]

21. Khouba, Z.; Benabdallah, T.; Maschke, U. Spectrophotometric study of liquid crystals containing pentadentate Schiff base type systems. Phys. Procedia 2009, 2, 1305-1311. [CrossRef]

22. Luckhurst, G.; Gray, G.W. The Molecular Physics of Liquid Crystals; Academic Press: Cambridge, MA, USA, 1979.

23. Saccone, M.; Kuntze, K.; Ahmed, Z.; Siiskonen, A.; Giese, M.; Priimagi, A. ortho-Fluorination of azophenols increases the mesophase stability of photoresponsive hy-drogen-bonded liquid crystals. J. Mater. Chem. C 2018, 6, 9958-9963. [CrossRef]

24. Jessy, P.; Radha, S.; Patel, N. Morphological, optical and dielectric behavior of chiral ne-matic liquid crystal mixture: Study on effect of different amount of chirality. J. Mol. Liq. 2018, 255, 215-223. [CrossRef]

25. Mishra, R.; Hazarika, J.; Hazarika, A.; Gogoi, B.; Dubey, R.; Bhattacharjee, D.; Singh, K.N.; Alapati, P.R. Dielectric properties of a strongly polar nematic liquid crystal compound doped with gold nanoparticles. Liq. Cryst. 2018, 45, 1661-1671. [CrossRef]

26. Altowyana, A.S.; Mostafa, A.M.; Ahmed, H.A. Effect of the liquid media and laser energy on the preparation of Ag nanoparticles and their nanocomposites with Au nanoparticles via laser ablation for optoelectronic applications. Optik 2021. [CrossRef]

27. Khushaim, M.S.; Alalawy, H.H.; Naoum, M.M.; Ahmed, H.A. Experimental and computational simulations of nematogenic liquid crystals based on cinnamic acid in pure and mixed state. Liq. Cryst. 2021. [CrossRef]

28. Takezoe, H.; Takanishi, Y. Bent-Core Liquid Crystals: Their Mysterious and Attractive World. Jpn. J. Appl. Phys. 2006, 45, 597-625. [CrossRef]

29. Ahmed, H.A.; Hagar, M.; El-Sayed, T.H.; Alnoman, R.B. Schiff base/ester liquid crystals with differ-ent lateral substituents: Mesophase behaviour and DFT calculations. Liq. Cryst. 2019, 46, 1-11. [CrossRef]

30. Capar, M.I.; Cebe, E. Molecular dynamic study of the odd-even effect in some 4- $n$-alkyl-4'-cyanobiphenyls. Phys. Rev. E 2006, 73, 061711. [CrossRef]

31. Capar, M.I.; Cebe, E. Odd-even effects in the homologous series of alkyl-cyanobiphenyl liquid crystals: A molecular dynamic study. J. Comput. Chem. 2007, 28, 2140-2146. [CrossRef]

32. Imrie, C.T.; Henderson, P.A. Liquid crystal dimers and higher oligomers: Between monomers and polymers. Chem. Soc. Rev. 2007, 36, 2096-2124. [CrossRef] [PubMed]

33. Saha, R.; Babakhanova, G.; Parsouzi, Z.; Rajabi, M.; Gyawali, P.; Welch, C.; Jákli, A. Oligomeric odd-even effect in liquid crystals. Mater. Horiz. 2019, 6, 1905-1912. [CrossRef]

34. Dave, J.; Patel, P.; Vasanth, K. Mixed mesomorphism in binary systems forming smec-tic-nematic phases. Mol. Cryst. 1969, 8, 93-100. [CrossRef]

35. Dave, J.S.; Menon, M.R.; Patel, P.R. Chiral phases induced by doping nonmesogenic com-ponent into mesogenic esters. Mol. Cryst. Liq. Cryst. 2003, 392, 83-95. [CrossRef]

36. Vora, R.A.; Gupta, R.; Patel, K. Exhibition of Induced Mesophases in the Binary Systems where One or Both the Components are Non-Mesogenic. Mol. Cryst. Liq. Cryst. 1991, 209, 251-263. [CrossRef]

37. Fujimura, S.; Yamamura, Y.; Hishida, M.; Nagatomo, S.; Saito, K. Reentrant nematic phase in 4-alkyl-4'-cyanobiphenyl (nCB) binary mixtures. Liq. Cryst. 2014, 41, 927-932. [CrossRef]

38. Prasad, A.; Das, M.K. Determination of elastic constants of a binary system $(7 \mathrm{CPB}+\mathrm{CN})$ showing nematic, induced smectic Ad and re-entrant nematic phases. Liq. Cryst. 2014, 41, 1261-1268. [CrossRef]

39. Salud, J.; Lopez, D.; Diez-Berart, S.; de la Fuente, M.R. Tests of the tricritical point in the SmA-to-N phase transition of binary mixtures butyloxybenzylidene octylaniline and hex-yloxybenzylidene octylaniline. Liq. Cryst. 2013, 40, 293-304. [CrossRef]

40. Vora, R.A.; Rajput, S.J. Binary Mesogenic Systems Comprised of Ester Mesogens and Non-Mesogens. Mol. Cryst. Liq. Cryst. 1991, 209, 265-277. [CrossRef]

41. Govindaiah, T.; Nagappa; Sathyanarayana, P.; Mahadeva, J.; Sreepad, H.R. Induced chiral smectic phase in mixtures of mesogenic and non-mesogenic compounds. Mol. Cryst. Liq. Cryst. 2011, 548, 55-60. [CrossRef]

42. Lohar, J.; Dave, J.S., Jr. Emergence of smectic mesophase in binary mixtures of pure nem-atogens. Mol. Cryst. Liq. Cryst. 1983, 103, 181-192. [CrossRef]

43. Sarkar, S.D.; Choudhury, B. Study of binary mixtures of two liquid crystalline samples showing induced smectic phase. Assam Univ. J. Sci. Technol. 2010, 5, 167-168.

44. Ahmed, H.; Naoum, M. Mesophase behavior of binary and ternary mixtures of benzoic acids bearing terminal substituents of different polarity and chain-lengths. Thermochim. Acta 2014, 575, 122-128. [CrossRef]

45. Alhaddad, O.A.; Ahmed, H.A.; Hagar, M.; Saad, G.R.; Al-Ola, A.; Khulood, A.; Naoum, M.M. Thermal and Photophysical Studies of Binary Mixtures of Liquid Crystal with Dif-ferent Geometrical Mesogens. Crystals 2020, 10, 223. [CrossRef] 
46. Naoum, M.M.; Mohammady, S.Z.; Ahmed, H.A. Lateral protrusion and mesophase behaviour in pure and mixed states of model compounds of the type 4-(4'-substituted phenylazo)-2-(or 3-)methyl phenyl-4'-alkoxy benzoates. Liq. Cryst. 2010, 37, $1245-1257$. [CrossRef]

47. Al-Zahrani, S.A.; Ahmed, H.A.; El-atawy, M.A.; Abu Al-Ola, K.A.; Omar, A.Z. Synthetic, Meso-morphic, and DFT Investigations of New Nematogenic Polar Naphthyl Benzoate Ester Derivatives. Materials 2021, 14, 2587. [CrossRef]

48. Laila, A.A.; Latifah, A.A.; Sobhi, M.G.; Hoda, A.A. Synthesis, thermal and optical characterizations of new lateral organic systems. Crystals 2021, 11, 551.

49. Gomha, S.M.; Abdelhady, H.A.; Hassain, D.Z.H.; Abdelmonsef, A.H.; El-Naggar, M.; Elaasser, M.M.; Mahmoud, H.K. Thiazole based thiosemicarbazones: Synthesis, cytotox-icity evaluation and molecular docking study. Drug Des. Dev. Ther. 2021, 15, 659-677. [CrossRef]

50. Gomha, S.M.; Muhammad, Z.A.; Abdel-Aziz, H.M.; Matar, I.K.; El-Sayed, A.A. Green synthesis, molecular docking and anticancer activity of novel 1,4-dihydropyridine-3,5-Dicarbohydrazones under grind-stone chemistry. Green Chem. Lett. Rev. 2020, 13, 6-17. [CrossRef]

51. Gomha, S.M.; Edrees, M.M.; Muhammad, Z.A.; Kheder, N.A.; Melha, S.A.; Saad, A.M. Synthesis, Characterization, and Antimicrobial Evaluation of Some New 1,4-Dihydropyridines-1,2,4-Triazole Hybrid Compounds. Polycycl. Aromat. Compd. 2020, 1-13. [CrossRef]

52. Gomha, S.M.; Riyadh, S.M. Synthesis under Microwave Irradiation of [1,2,4]Triazolo[3,4-b] [1,3,4]thiadiazoles and Other Diazoles Bearing Indole Moieties and Their Antimicrobial Evaluation. Molecules 2011, 16, 8244-8256. [CrossRef]

53. Abu-Melha, S.; Edrees, M.M.; Riyadh, S.M.; Abdelaziz, M.R.; Elfiky, A.A.; Gomha, S.M. Clean grinding technique: A facile synthesis and in silico antiviral activity of hydrazones, pyrazoles, and pyrazines bearing thiazole moiety against SARS-CoV-2 main protease (M $\left.{ }^{\text {pro }}\right)$. Molecules 2020, 25, 4565. [CrossRef] [PubMed]

54. Sayed, A.R.; Gomha, S.M.; Taher, E.A.; Muhammad, Z.A.; El-Seedi, H.R.; Gaber, H.M.; Ahmed, M.M. One-Pot Synthesis of Novel Thiazoles as Potential Anti-Cancer Agents. Drug Des. Dev. Ther. 2020, 14, 1363-1375. [CrossRef]

55. Ouf, S.A.; Gomha, S.M.; Ewies, M.; Ouf, A.S.; Sharawy, I.A.A.; Alharbi, S.A. Antidermatophytic activity of some newly synthesized arylhydrazonothiazoles conjugated with monoclonal antibody. Sci. Rep. 2020, 10, 20863. [CrossRef] [PubMed]

56. Rashdan, H.; Abdelmonsef, A.; Shehadi, I.; Gomha, S.; Soliman, A.; Mahmoud, H. Synthesis, Molecular Docking Screening and Anti-Proliferative Potency Evaluation of Some New Imidazo[2,1-b]Thiazole Linked Thiadiazole Conjugates. Molecules 2020, 25, 4997. [CrossRef] [PubMed]

57. Gomha, S.M.; Abdel-aziz, H.M. Synthesis and antitumor activity of 1, 3, 4-thiadiazole derivatives bearing coumarine ring. Heterocycles Int. J. Rev. Commun. Heterocycl. Chem. 2015, 91, 583-592. [CrossRef]

58. Yeap, G.-Y.; Osman, F.; Imrie, C.T. Non-symmetric dimers: Effects of varying the meso-genic linking unit and terminal substituent. Liq. Cryst. 2015, 42, 543-554. [CrossRef]

59. Attard, G.; Date, R.; Imrie, C.T.; Luckhurst, G.R.; Roskilly, S.J.; Seddon, J.M.; Taylor, L. Non-symmetric dimeric liquid crystals the preparation and properties of the $\alpha$-(4-cyanobiphenyl-4'-yloxy)- $\omega-\left(4-n\right.$-alkylanilinebenzylidene- $4^{\prime}$-oxy) alkanes. Liq. Cryst. 1994, 16, 529-581. [CrossRef]

60. Aulsebrook, M.L.; Graham, B.; Grace, M.; Tuck, K. Coumarin-based fluorescent sensors for zinc(II) and hypochlorite. Supramol. Chem. 2015, 27, 798-806. [CrossRef]

61. Huang, X.; Dong, Y.; Huang, Q.; Cheng, Y. Hydrogen bond induced fluorescence recovery of coumarin-based sensor system. Tetrahedron Lett. 2013, 54, 3822-3825. [CrossRef]

62. Veerabhadraswamy, B.N.; Rao, D.S.S.; Yelamaggad, C.V. Ferroelectric liquid crystals: Synthesis and thermal behavior of optically active, three-ring Schiff bases and salicylal-dimines. Chem. Asian J. 2018, 13, 1012-1023. [CrossRef] [PubMed] 